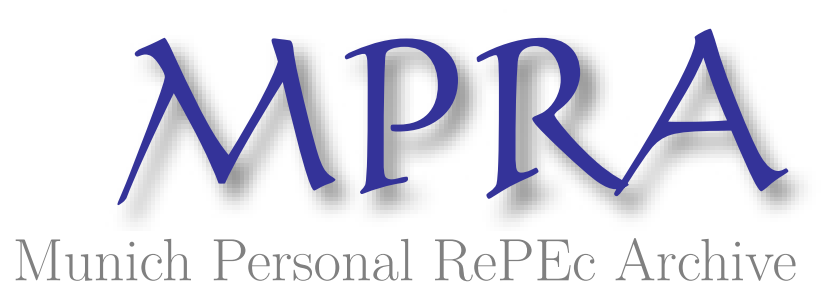

\title{
Dishonesty, Social Information, and Sorting
}

\author{
AKIN, ZAFER
}

1 August 2018

Online at https://mpra.ub.uni-muenchen.de/90412/

MPRA Paper No. 90412, posted 12 Dec 2018 14:02 UTC 


\title{
Dishonesty, Social Information, and Sorting
}

\section{ZAFER AKIN ${ }^{1}$}

\section{August 2018}

\begin{abstract}
The dishonesty literature investigates how people behave when they are provided certain types of information. However, this approach predominantly ignores the fact that people -to some extent- can choose which information they want to be exposed to. By conducting a laboratory experiment, we study individuals' decisions to choose which social information they would like to observe and the effect of this sorting on their engagement in unethical conduct. We find evidence that sorting exacerbates the prevalence of dishonesty, which is mainly driven by the ones who chose maximum information. Our results demonstrate that sorting is an important factor determining dishonest behavior and that previously observed levels of prevalence of dishonesty in the literature can be an underestimate of actual level of dishonest behavior in real-world situations.
\end{abstract}

Key Words: Dishonesty; social norms; selection; laboratory experiments

JEL Classification: C91; D03

PsycINFO Classification: 2260; 2360

\footnotetext{
${ }^{1}$ Associate Professor of Economics, +90 530310 8797, zaferakin@gmail.com. Orcid ID: 0000-0001-5904-0494. I gratefully acknowledge the partial financial support of the Scientific and Technological Council of Turkey. I thank Selçuk Özyurt, Michael I. Norton, Francesca Gino and participants at $2^{\text {nd }}$ Turkish Workshop on Experimental and Behavioral Economics for helpful comments. I also thank Mücahit Denk, Serap Sağır, İhsan Furkan Kılıç for their help during data collection. Marie Claire Villeval has given considerable comments on the manuscript, I especially thank her for helpful suggestions. I also thank several anonymous referees for helpful comments and suggestions.
} 


\section{Introduction}

Honesty is a strong and desirable norm in every society. However, dishonesty is a prevalent reality we frequently face in almost each and every part of the society. From corporate world to family life, from government to personal relationships, we always observe, hear examples of dishonesty and often times become victims of these acts. These frequent direct and indirect encounters naturally give rise to the question that how exposure to others' dishonest behavior affects individuals' dishonesty.

The literature, investigating how others' dishonesty affect one's own unethical conduct, exogenously provide certain types of social information to the subjects and examine their reaction. In this literature, there is no consensus about whether and how information about others' dishonesty (social information) affect the prevalence of dishonesty. While there are some studies showing that dishonesty is somewhat contagious (Diekmann et al. 2015; Gino et al. 2009; Innes \& Mitra 2013; Lefebvre et al. 2015), there are other studies that find null effects of social information provision ${ }^{2}$ (Abeler et al. 2016; Innes \& Mitra 2013; Kroher \& Wolbring, 2015; Lefebvre et al. 2015; Mazar et al. 2008; Rauhut, 2013). In spite of this disagreement on the effects of social information, these studies have one common design feature that they all impose social information on the participants and overlook the fact that people can choose, to some extent, which information they would like to encounter. We tend to search for, interpret or remember information that are aligned with our own beliefs or behavior and ignore the ones that contradict with the way we -would like to- believe or behave (confirmation bias; Wason, 1960). Namely, people tend to reach and process available information selectively (Gino et al. 2016). This tendency potentially influences formation of our moral codes, e.g. honesty perception, too.

In this paper, our research question is whether and how individuals' engagement in unethical behavior changes when sorting into environments with different social information is possible. We address this question by incorporating selective perception possibility in information selection into an environment in which people can behave dishonestly. Specifically, we first explore how different social information (average or maximum score of others) influence individuals' behavior in a task in which cheating is possible. Then, more importantly, we study which social information individuals would like to have access when they are given the opportunity and the effect of this sorting on their engagement in unethical conduct. Due to our implicit or explicit preference for observing/recognizing self-confirmatory information more, this sorting possibility should be incorporated in experimental settings. For example, although there may be exogenous factors and constraints, we can choose which neighborhood to live in, people that we interact with, media channels that we want to get information/news etc. Since the set of

\footnotetext{
${ }^{2}$ Gino et al. (2009) show that dishonesty may even be mitigated under some conditions.
} 
ethical norms is an integral part of society, these choices also reflect the ethical norms that we will be exposed to and prefer. Thus, including such sorting options in laboratory experiments is a realistic and plausible approach.

We argue that sorting possibilities may exacerbate dishonesty. The main rationale behind this argument is the fact that people have advanced abilities to solve internal conflicts through self-serving justifications in situations involving possible dishonest acts (e.g., Gino et al. 2013a; Gino \& Ariely, 2012; Shalvi et al. 2011; Houser et al. 2012). With sorting, people who actually cheat or who have comparatively stronger tendencies to cheat are able to choose to observe other people who cheat. This choice potentially makes solving their internal conflicts easier because they incur less cost from cheating with this knowledge. In this way, they are able to cheat more and/or cheat more comfortably. We expect that more prevalent dishonesty under sorting will be mainly driven by the ones who sort into maximum information option.

Although the idea of incorporating sorting opportunities into dishonesty contexts seem plausible, it is generally disregarded in the existing literature. In real-world settings, we are not usually exposed to ostentatiously taken dishonest acts as in Gino et al. (2009); instead, these acts are mostly tried to be concealed and not explicitly made known. Lefebvre et al. (2015) provided information about the highest and the lowest evasion rates of others as if those are prevailing norms and investigated norm compliance argument. Similarly, subjects in Innes and Mitra (2013) were assigned to four different treatments in which they played the deception game (Gneezy, 2005) and in each treatment they were provided different percentages of untruthful senders. Other studies provided either information about average behavior directly (Mazar et al. 2008) or the distribution of payoffs (Diekmann et al. 2015; Kroher \& Wolbring, 2015; Rauhut, 2013). None of the mentioned studies allowed subjects to choose information. However, directly providing these types of information may not reflect real life situations. First, we generally are neither able to observe the prevailing norm nor not exposed to all kinds of behavior in the society we live in. Instead, we frequently observe and hear incidences that are in the extremes (predominantly the "bad" ones) that is probably because the average person's behavior does not attract much attention. Second, we have a tendency to selectively perceive what happens in our surroundings that may make us inclined to recognize especially these extreme behavior and what we would like to see.

These observations necessitate a different approach to understand the interaction between social information and dishonest behavior. We use a laboratory experiment to identify this interaction that enables us to randomly form groups, control what information subjects have access, and allow them to sort into different informational environments in a controlled way. Our design involves a paper-pencil two-stage matrix task that allows dishonest behavior introduced by Mazar et al. (2008). In the first stage, 
matrix task is performed without any social information disclosure. In the second stage, matrix task is again performed only after -in the information treatments- social information feedback is received. Namely, either average score or maximum score of others, who participated in the same experiment previously without getting this information, is provided. We run these treatments primarily to compare them with the results in the sorting treatment in which subjects can choose which of these two types of information they would like to learn just before performing the second matrix task. We conduct our experiment with a between subject design. Since the first stage is the same across all treatments, we can check whether randomization across treatments and control is done properly by comparing the first stage scores and we are able to classify different patterns of behavior more precisely since we observe subjects' ex-ante and ex-post behavior by analyzing anonymous individual level data. Therefore, our design mimics real world situations in which someone who is in an environment she can potentially cheat may selectively perceive social information. Of course, our approach is not able to cover much more complex real world sorting decision environments, but it can be considered as a first step to understand the interplay between immoral acts and social information selection.

Our findings imply that sorting opportunity is a significant factor. We show that the ones who chose to see the maximum information engage in unethical behavior significantly more than people who are imposed maximum information while unethical behavior of people who are imposed average information is not significantly different from the ones who chose to see this information. Moreover, relative to the case of providing no information, imposing neither the information about average behavior nor the extreme behavior leads to a significant change in dishonest behavior while the sorting opportunity exacerbates the prevalence of dishonesty. This result is mainly driven by cheaters whose definition will be given shortly because they choose maximum information more relative to non-cheaters.

One important practical implication of our findings is about revealing information regarding people's performance. One overlooked consequence of revealing information that should reflect true performances is that it may be perceived incorrectly. If some people selectively perceive and interpret it as a proof of some people undeservingly becoming top performers, this may lead them astray. In other words, some people may interpret these extreme acts (although it is evident that high reports are unethical in our case) as a signal of unethicality and may justify their own. Thus, in an organizational context, decision of revealing performances including extreme ones should be taken carefully since it may pave the way for people seeking justification for their dishonesty.

The rest of this paper is organized as follows. In section 2, we review the relevant literature. In section 3, we describe the experimental design and the procedure. In section 4, we present our results. In section 5, we discuss the main findings and conclude. 


\section{Related Literature}

Both theoretical and experimental research about dishonesty has expanded rapidly in the last years. Economists naturally model dishonesty as a rational decision problem whose only ingredients are material reward gained by behaving dishonestly, expected punishment and the likelihood of being caught. These standard models imply that if expected punishment and/or the likelihood of being caught is low enough, then we should see people cheating maximally. However, recent studies showed that although dishonesty is prevalent, it is limited and well below the maximum possible level. ${ }^{3}$ The broader implication of these studies is that, in addition to instrumental motivations economists assume, there are other motives behind dishonest behavior. For example, Abeler, Nosenzo and Raymond (2016) in their comprehensive paper consider three types of plausible motivations: Implicit or explicit lying costs (preference for being honest), reputational concerns (preference for being seen as honest) and social norms/comparisons (preference for conformity). A complex interaction among these motivations determine the extent of individuals' engagement in unethical behavior. In this paper, we would like to point out a different factor that may influence this interaction.

The literature's general approach to understand dishonesty is methodologically standard: Analyzing how people -who have a chance to cheat- behave who are randomly assigned to different conditions. Randomization is crucial and at the heart of all experimental economic studies. However, in real life, individuals often sort into and out of different environments/groups based on their preferences and in response to relative prices. There are studies that have addressed possible effects of sorting in different contexts. For example, Ahn et al. (2008) allowed for endogenous group formation in public good context and found that rules of formation of groups have significant impact both on individual and group behavior. Lazear et al. (2012) showed that allowing subjects to sort into and out of environments in which sharing is possible significantly reduces sharing which implies that there are individuals who share reluctantly when they find themselves in a sharing environment but if given the chance, they avoid these environments. ${ }^{4}$ Almost all research investigating sorting in different contexts found a significant effect of

${ }^{3}$ See Abeler et al. (2016) for extensive meta-analysis and theoretical exposition for partial lying. See also Khalmetski and Sliwka (2017) and Gneezy et al., (2018) for other recent theoretical models. Specifically see, for example, Charness, Masclet and Villeval (2013) for the effect of ranking feedback and competition; Chytilova and Korbel (2014) for differences between group and individual behavior; Cojoc and Stoian (2014) for the effect of having opportunity to help others on dishonesty; Gino, Ayal and Ariely (2009) and Innes and Mitra (2013) for contagiousness of dishonesty; Gino and Ariely (2012) and Gino, Ayal and Ariely (2013a) for effects of beneficiaries, and Mazar, Amir and Ariely (2008) for the trade-off between self-concept and self-benefit. See also Irlenbusch and Villeval (2015) for a review of recent research on the determinants of unethical behavior.

${ }^{4}$ Dana et al. (2006), Dana et al. (2007) and Grossman (2014) also examine sorting in altruistic sharing context. There are other studies investigating effects of sorting in different contexts as well. For example: Villeval and Eriksson (2004) allowed employers to choose incentive contracts; Gürerk, Irlenbusch and Rockenbach (2006) and Haigner, 
sorting on the relevant behavior. We argue that the results of the existing studies imposing informational, organizational or social factors on people may be somewhat biased in terms of the prevalence of dishonesty because reporting decisions of people who potentially care about injunctive and descriptive social norms are informed by the imposed information that they may prefer to disregard outside the laboratory. Thus, this may lead to different decisions relative to cases where decision makers are free to choose which information to observe.

There are very limited number of studies that touch on this overlooked factor of sorting possibilities in the context of dishonesty. Motivated by the observations that firms can choose their locations having different institutional regulations, Gino et al. (2013b) studied people's willingness to bypass regulations and found that existence of avoidable regulations exacerbates dishonesty relative to the case of no regulation (they get the "license to cheat"). Faravelli et al. (2015) endogenized the selection of payment scheme and showed that ones with a higher propensity to be dishonest are more likely to sort into competition. Blackburn et al. (2014) empirically examined cheating behavior in online games and showed the existence of group formation based on people's propensity to cheat. Findings of these papers imply that results in the related literature without sorting may be a lower bound of the actual level of dishonesty with sorting. This generalization cannot be made safely unless it is more widely tested. Our paper aims to contribute to this literature by specifically allowing subjects to choose which social information to observe and by comparing their behavior with the behavior of the ones who are imposed this information.

The reason why we argue that sorting opportunities may exacerbate dishonesty is the ability of people to deal with internal conflicts that arise when cheating is possible. Gino and Ariely (2012) showed that having a creative personality and mindset promotes people's ability to justify their dishonesty. Gino, Norton and Weber (2016) extensively examined the tendency of people -motivated Bayesians- to engage in motivated information processing to solve the conflict between acting egoistically and acting morally. Gino et al. (2013a) showed that people engage in ethical misconduct more when others can benefit from their cheating. Cojoc and Stoian (2014) found that when people have opportunity to help others later on, they act more dishonestly. Shalvi et al. (2011) showed that people tend to perceive their unethical behavior more acceptable in the existence of counterfactuals. Houser et al. (2012) showed that individuals are more likely to engage in unethical behavior if they believe that they were previously treated unfairly. Finally, Shalvi et al. (2015) presented a general framework and highlighted underlying psychological mechanisms of self-serving justifications emerging before and after people engage in dishonest behavior.

Kocher, and Sutter (2006) allowed choosing institutions having either sanctions or not in a public goods context; Slonim and Garbarino (2008) investigated the effects of the partner selection in trust and dictator games, and Niederle and Vesterlund (2007) studied how selective entry into competitive environments affects behavior. 
Our design contributes to this literature by allowing subjects to choose to observe either the extreme or the average behavior of others that can be used to justify their behavior. As far as we know, there is no other study that directly provides sorting opportunities based on social information in the context of dishonesty.

Provision of social information that allows people to learn about what others do has been recently attracting attention. It is hard to talk about any convergence in the results of existing studies although there are some consistent findings when the level of social information is taken into account. On the one hand, there are studies that find some effect of social information on dishonesty. Diekmann et al. (2015) employed a dice casting task (Fischbacher and Heusi, 2013) and showed that informing subjects about the distribution of others' reports that heavily differs from the distribution of a fair dice increased their propensity to lie compared to no information condition. Fosgaard et al. (2013) in one treatment gave subjects the signal that all previous subjects cheated and found that this increased their level of cheating. Gino et al. (2009) showed that when a dishonest act by a person with an in-group/out-group identity is ostentatiously taken, people increase/decrease their dishonesty. Innes and Mitra (2013) presented subjects information about the percentage of untruthful senders in the deception game (Gneezy, 2005). They provided four different percentages of past participants $(15 \%, 40 \%, 60 \%$ and $85 \%)$ and showed that only the heavily untruthful (85\%) treatment exacerbated untruthfulness relative to no information group in Arizona where subjects are predominantly honest (this finding is parallel to what Cialdini et al. (1990) found in the context of littering in public places). They also showed that honesty can prevail in Calcutta where subjects are predominantly dishonest when they get the heavily truthful (15\%) message. Their results imply that (dis)honesty can be contagious if beliefs about norms substantially contradict with the provided social information. In the context of tax evasion, Lefebvre et al. (2015) examined how individuals' occupational choice and tax evasion decisions are affected by the provided information regarding others' tax compliance. They provided information about the highest and the lowest evasion rates of others as if these are the prevailing norms and found a similar asymmetric effect in which only high evasion information exacerbated tax evasion.

On the other hand, there is also evidence that people are unaffected by what others are doing. Mazar et al. (2008) provided information about the number of matrices that the average student solved (the real report average in one treatment, two times of the real report in the other) and found that the level of cheating is independent of information about the average reported performance of others. Rauhut (2013) used a repeated dice casting task by informing subjects about the frequency of each reported payoff and showed that this information has positive but insignificant effect on misreporting. A significant effect is observed only when comparing subjects' scores with initially high beliefs about the distribution of scores to the subjects' scores with initially low beliefs. However this evidence should be 
treated with caution because the treatment is not fully randomly assigned. Kroher and Wolbring (2015) conducted a similar dice roll (lab and online) experiment by informing subjects about the whole score distribution obtained from the same previous experiments. They also found a similar result of a small and non-significant increase of cheating in the information feedback group. Abeler et al. (2016) has a different approach: Subjects were not provided the actual past behavior of others but their beliefs about the report distribution is manipulated by an anchoring procedure. They show that manipulating beliefs about others' dishonest behavior does not have any effect on subjects' own dishonesty. Furthermore, as mentioned above, Innes and Mitra (2013) found no difference in dishonesty for low levels of feedback (15\%, 40\% and 60\%) and Lefebvre et al. (2015) found that providing low tax evasion information does not make any change in subjects' tax evasion decisions.

Given the results of these studies, the evidence on contagiousness of dishonesty is mixed and divergent. It seems that the level of provided social information matters. The level of observed dishonesty seem to be not affected by what others do except those cases where subjects are informed or believe that others are heavily dishonest. We can deduce this from the findings of Fosgaard et al. (2013) that cheating increases when the information that all participants in the same session cheated before is given; Gino et al. (2009) in which existence of an observable reckless cheater exacerbates dishonesty; Lefebvre et al. (2015) in which only maximum information (reported percentages ranged between $71 \%$ and $78 \%$ for different income groups with an average of 74\%) increases tax evasion and Innes and Mitra (2013) finding that only heavily untruthful report (85\%) intensifies dishonesty. In Abeler et al. (2016), induced average beliefs of subjects about the percentage of other participants reporting high outcome are $41 \%$ and $62 \%$ in high and low treatments while the true percentage should be $10 \%$. These beliefs are far from extreme and this null effect they found supports our conclusion. Mazar et al. (2008) supports our conclusion as well since they informed subjects that other participants solved only 4 and 8 matrices out of 20 and found no effect. Unfortunately, from the papers using die casting experiment, it is difficult to make an inference regarding our conclusion because subjects see the whole score distribution that clearly indicates that others cheated but it is up to them how to interpret this distribution.

In our paper, we provide our participants average scores of subjects who previously participated the same experiment. By this way, we are able to both present further evidence regarding the role of social norms on dishonest behavior and compare these results especially with the ones who chose to see average information in the sorting treatment. By the above argument, if the average report had turned out to be very high (we provide the average truthfully as opposed to Mazar et al. 2008, for example) then we could have expected increasing dishonesty. However, since the average reported score turned out to be 10 out of 
20 which can be considered as a mild cheating, we expect that showing average information will have no effect on the prevalence of dishonesty relative to the base treatment.

Moreover, in a different treatment, we provide subjects maximum score information of others who participated this experiment previously. Thus, we are able to test whether and how imposing maximum information differs from allowing to choose it in terms of dishonest behavior. When a subject learns that the reported maximum score is actually the maximum possible score, he/she can deduce that there is no risk of being caught cheating and this tends to increase dishonesty according to rational crime theory, Becker (1968). Another possible way this observation change one's own dishonesty is related to the saliency of ethicality at the decision moment. Saliency channel emphasizes that when unethical act is made salient, people may pay greater attention to their own moral standards that could lead to reduced dishonest behaviors. By informing subjects about the maximum score, we are able to test these proposed mechanisms that have opposite effects on people's propensity to act dishonestly.

Overall, our design allows us both to see to what extent people engage in cheating behavior and determine the effect of average and maximum information. Moreover, we take a more realistic approach by allowing sorting with an active choice of information. Our design has the potential to unveil how people choose and interpret social information in making ethical decisions.

\section{Experimental Design and Procedures}

\subsection{Experimental Design}

In our experiment, we have sorting and no-sorting treatments and a control group. In all treatments, cheating is allowed while it is not in the control. There are three no-sorting treatments. In the base treatment, no social information is provided. In the average and maximum treatments, subjects are informed about the average and maximum scores of the previous participants, respectively. There is only one sorting treatment in which individuals can choose social information, average or maximum information, they would like to observe. Table 1 summarizes the design of the experiment.

\begin{tabular}{|c|c|c|c|c|}
\hline \multirow[t]{3}{*}{ Control } & \multicolumn{3}{|c|}{ No Sorting } & \multirow[t]{3}{*}{ Sorting } \\
\hline & \multirow{2}{*}{ No Information } & Average & Maximum & \\
\hline & & Information & Information & \\
\hline$N=29$ & $N=32$ & $N=34$ & $N=37$ & $N=50$ \\
\hline No Cheating & Cheating-Base & Cheating-Ave & Cheating-Max & Cheating-Sorting \\
\hline
\end{tabular}

Table 1: Experimental Design Overview 
The experiment consists of two periods. In both periods, participants completed the matrix task (Mazar et al. 2008). In this task, participants receive a one-page worksheet with 20 matrices each of which contains 12 three-digit numbers and they are given five minutes to find two numbers that add up to 10 (e.g., 4.12 and 5.88). Participants earn 1TL for each matrix they correctly solve. Five-minute allotted time is generally insufficient for participants to solve all 20 matrices. A typical participant solves 4-5 matrices correctly in five minutes. We are primarily interested in the extent of misreporting in this task.

First period included only the matrix task and was same across all the treatments except control. In the control, participants self-reported their scores on the matrix task, and the experimenter explained that there would be verification of the scores. In other treatments, there was no verification (subjects shredded their task sheets). In the second period, subjects were first provided social information (except control and base treatment), then completed the matrix task again. In the average/maximum no-sorting treatments, subjects were given the average/maximum score of the participants from the second task who previously participated the same experiment and did not get this information. In the sorting treatment, subjects were given the choice to see either average or maximum score before starting second matrix task. By this two-period design, our aim was to make comparisons not only between control/base and treatments but also comparisons within subjects.

In the social information treatments, at the beginning of the second period, after the instructions, subjects were given either of the following information:

In the average treatment: The average earnings of the participants in the second matrix task you are about to start who joined the exact same experiment before is 10 TL (excluding show-up fee and first matrix task earnings). These participants did not get this information.

In the maximum treatment: The earning of the person who earns the highest amount in the second matrix task you are about to start among the participants who joined the exact same experiment before is 20 TL (excluding show-up fee and first matrix task earnings). These participants did not get this information.

Subjects chose to see one of these statements in the sorting treatment. Provided average (10 TL) and maximum values (20 TL) were the actual values endogenously determined in the second matrix task of the base treatment which was conducted before social information treatments. Note that individual dishonesty could not be detected in our design because participants were able to take any amount up to 20 TL for each matrix task regardless of their actual performances that were completely unverifiable. ${ }^{5}$

\footnotetext{
${ }^{5}$ Moreover, 10 out of 20 matrices were not solvable in both matrix sheets. Thus, the ones leaving less than 10TL in the money envelopes were surely cheaters. We call these people as sure-cheaters.
} 
Moreover, to be able to see the sole effect of different information on dishonest behavior, we did not allow for institutional or individual/group sanctions.

Finally, subjects filled out a survey asking for demographics such as age, gender, major, income, work experience etc. and personality traits (such as risk taking, competitiveness, religiosity etc.). We chose these measures due to their potential relevance with dishonest behavior shown in previous studies. In the sorting treatment, we also asked subjects which information they chose and why.

\subsection{Procedures}

Our experiment was conducted in a university in one of the big cities of Turkey. Eight sessions were run with a total of 182 volunteer student participants. A session lasted 45-50 minutes. ${ }^{6}$ On average, participants earned 25 Turkish Lira (1TL $\sim \$ 0.35$ at the time of the experiment) including 5TL show-up fee. ${ }^{7}$ We had a between-subject design in which each subject participated in only one session. Upon arrival, participants were randomly seated alone at tables on which there are high and wide enough separators and tables were far enough from each other. The whole experiment was conducted in a non-computerized (paper-pencil) environment. After completing the consent form, instructions (see appendix 2) were read aloud and participants were told that they would receive a show-up fee and might earn additional money.

The experiment was composed of two periods. Instructions included three parts. The first part informed participants about the general structure of the experiment and was common in all treatments. The second part was about the first period of the experiment and explained the matrix task. This part was the same across all the treatments except control. The third part was about the second period of the experiment and included explanations for the same task and social information.

When subjects arrived, they found a big white (C3 size) envelope on the table that contains all the documents for the experiment. Last part of the (second period) instructions, a matrix sheet, a white money (DL size) envelope and a yellow (C4 size) envelope were located in the big envelope. First money envelope contained 20TL (one 10TL bill, one 5TL bill and five 1TL coins). The yellow envelope was used in the second period which contained a matrix sheet, a money envelope and a one-page survey sheet (in social information treatments, information envelopes were located too). This second money envelope contained 20TL plus 5TL show-up fee. With the experimenter's directives, subjects followed the steps

\footnotetext{
${ }^{6}$ To make sure that random sampling is done correctly, we first ran base and control treatments. After a period of time, we invited participants for other treatments as if this was a different experiment and screened early participants. To prevent information spillover and rule out session effects, in two parallel sessions of social information treatments, there were subjects who see average or maximum information in the same session. Immediately after these treatments, we ran one large session of sorting treatment without allowing subjects to interact with early participants.

${ }^{7}$ Minimum hourly wage in Turkey was approximately $9.11 \mathrm{TL}$ after tax at the time. On average, 15-20 TL per hour net wage is a common practice in experimental studies in Turkey.
} 
(see appendix-1A and appendix-1B). The opportunity to behave dishonestly was implemented via the selfpayment scheme (Gino et al. 2009). At the end of five minutes, subjects were asked to drop their pens. They were instructed to count how many matrices they solved by themselves, then to walk to the shredder and shred their matrix sheets. When they went back to their seats, they were asked to take 1TL from the money envelope for each matrix they solved. At this point, since there was no verification, they were free to take as much money as they wanted from the money envelope. After subjects paid themselves, they were requested to seal these self-seal money envelopes. This allowed us to detect the extent of dishonesty. ${ }^{8}$ Only in the control, at each period, we collected the matrix sheets after five minutes, verified subjects' correct answers and privately paid them based on their score.

In the no sorting treatment, social information was written on a slip and placed in a sealed white small square (C6 size) envelope. This information envelope was placed in the big yellow envelope; subjects opened and read the information just before they started the second matrix task. In the sorting treatment, participants could choose which type of information they wanted to see. We placed the average/maximum information slip into a sealed green/orange small square envelope. Both green and orange envelopes were placed into the big yellow envelope. Just before they started working on the second matrix task, they were instructed to open only one of these envelopes and read the information slip.

At the end of the second period, subjects filled out a survey. After completing survey, participants were requested to place every document back into the big white envelope and seal it (in the control, they brought the envelopes to the experimenter and they left). Subjects left the room after dropping this envelope to the recycling box next to the exit door.

\section{Results}

Table 2 summarizes subjects' scores for all the treatments. The first obvious result is that people cheat when they are given the opportunity but not to the maximum possible extent which supports previous findings (e.g., Abeler et al. 2016; Gino et al. 2009; Mazar et al. 2008). Means in control and base treatments are significantly different $\left(t_{59}=4.49, \mathrm{p}<0.0001 ; t_{59}=5.06, \mathrm{p}<0.0001\right.$; for period 1 and 2 , respectively).

\footnotetext{
${ }^{8}$ In the instructions, in order to secure full anonymity, subjects were repeatedly reminded not to write any information on any of the documents that might reveal their identity. During the whole procedure, the experimenter remained at or around his desk and did not intervene in any of the process. By this design, we are not able to match envelopes with subjects but we have each individual's decisions at each period along with his/her survey data.
} 


\begin{tabular}{|c|c|c|c|c|c|c|c|}
\hline \multirow[b]{2}{*}{ Treatment } & \multicolumn{3}{|c|}{ Period 1} & \multicolumn{3}{|c|}{ Period 2} & \multirow[b]{2}{*}{ Social Information } \\
\hline & Mean & Min & Max & Mean & Min & Max & \\
\hline No Cheating (Control) & $3.68(2.01)$ & 0 & 8 & $5.17(2.18)$ & 1 & 9 & No \\
\hline Cheating (Base) & $8.93(5.97)$ & 0 & 20 & $10.78(5.58)$ & 2 & 20 & No \\
\hline Average & $9.70(7.11)$ & 1 & 20 & $11.29(6.81)$ & 1 & 20 & Yes - Provided \\
\hline Maximum & $7.22(5.50)$ & 0 & 20 & $9.05(6.07)$ & 1 & 20 & Yes-Provided \\
\hline Sorting (Pooled) & $10.18(7.43)$ & 0 & 20 & $13.36(6.61)$ & 1 & 20 & Yes - Elective \\
\hline Sorting (Average) & $8.42(6.75)$ & 0 & 20 & $10.80(6.40)$ & 1 & 20 & Yes $(\% 42)$ \\
\hline Sorting (Maximum) & $11.44(7.76)$ & 1 & 20 & $15.20(6.22)$ & 4 & 20 & Yes $(\% 58)$ \\
\hline
\end{tabular}

Table 2: Outcomes from Matrix Task by Condition

In order to check whether our random sampling process was robust, we used Kruskal-Wallis equality of population rank test. Since there was no intervention in period 1 in treatments, we expect the null hypothesis that these samples are from the same population cannot be rejected. The test reveals that this is indeed the case both for base, average and maximum treatments together $\left(\chi^{2}=1.977, p=0.37\right)$, and when pooled sorting treatment is added $\left(\chi^{2}=2.307, \mathrm{p}=0.51\right)$. One-way ANOVA also revealed no significant effect of treatments $(F(2,100)=1.50, p=0.23 ; F(3,149)=1.53, p=0.2)$. Thus, we can safely say that random sampling process worked well and subjects were assigned to the treatments randomly.

\subsection{Are Subjects Influenced by Others' Average or Extreme Behavior?}

There is no consensus in the previous literature about the effect of average information on dishonest behavior. Our analyses showed that providing information about average scores does not affect cheating behavior. Specifically, in the base treatment, average scores were 8.93 and 10.78 matrices while they were 9.70 and 11.29 for period 1 and 2 in the average treatment, respectively. These differences are not significant across treatments $\left(\mathrm{t}_{64}=-0.47, \mathrm{p}=0.31\right.$, for period $1 ; \mathrm{t}_{64}=-0.33, \mathrm{p}=0.37$, for period 2$)$. The average report turned out to be approximately 10 in the second period of the base treatment. As we argued, since this is far from being an extreme value, it is not expected to affect the behavior in the average treatment. Moreover, since what subjects did on average in the first period and the information they get at the beginning of the second period overlap almost exactly (9.70 and 11.29 are not significantly different from $10, t=0.24, p=0.81 ; t=1.1, p=0.27$, respectively), the average information seemed to be almost self-confirmatory and did not affect the behavior. As a result, providing average information has no effect on dishonesty.

As we argued, since having access to maximum information may trigger different opposing forces, dishonest behavior can either increase or decrease dishonesty. Our analyses showed that relative to the 
base treatment, providing information about maximum score has no effect on the level of dishonesty. Average scores in the maximum treatment are 7.22 and 9.05 for period 1 and 2, respectively and are not significantly different from base treatment scores $\left(\mathrm{t}_{67}=1.24, \mathrm{p}=0.10\right.$ for period $1 ; \mathrm{t}_{67}=1.22, \mathrm{p}=0.113$ for period 2). As a robustness check, when we tested whether in period 2, base, average and maximum treatment samples are drawn from the same population, the null hypothesis cannot be rejected (KruskalWallis test $\chi 2=2.881, \mathrm{p}=0.23$; one-way $\operatorname{ANOVA} \mathrm{F}(2,100)=1.28, \mathrm{p}=0.28$ ). Thus, as can also be seen from Figure 1, showing neither average nor maximum score significantly affects cheating behavior.

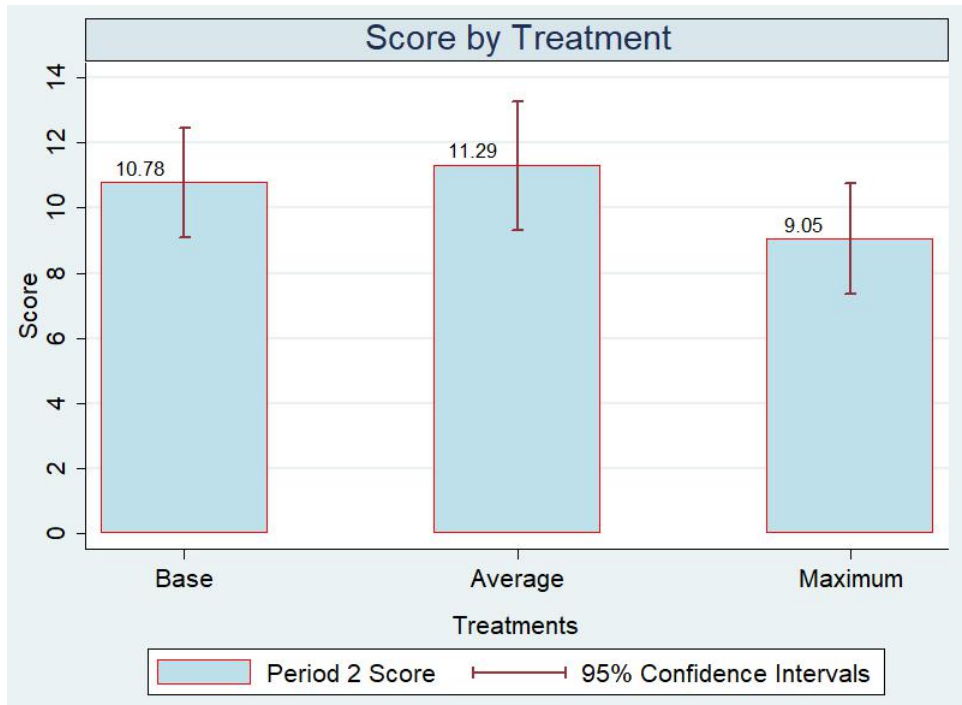

Figure 1: Reported score in Period 2 for no information/base, average information and maximum information treatments.

\subsection{No Social Information, Imposing It or Allowing Sorting?}

In order to answer our main question whether sorting has any effect on dishonesty, we need to compare the behavior of the ones who are imposed a specific information, namely average and maximum information, with the behavior of the ones who sort into the corresponding information environment. We showed that providing option to observe social information intensifies dishonesty in maximum information case while it makes no difference in average information case in terms of dishonesty.

The mean report of average information choosers can be expected to be lower than the mean of the average treatment due to differences in types (extreme ${ }^{9}$ and sure-cheaters) in two groups. Average treatment potentially includes all types of agents. However, in the sorting average treatment, it can be expected that there are dominantly people who are relatively honest. Specifically, data shows that ratios of

\footnotetext{
${ }^{9}$ Extreme cheaters are the ones who take all the money from any of the money envelopes and claim that they solved all 20 matrices.
} 
extreme and sure-cheaters are less in the sorting average treatment as expected, but these differences in ratios are not significant (see Table 3). The mean reports in average and sorting average treatments are 9.7 and 8.42 in period 1 and 11.29 and 10.80 in period 2, respectively (see Figure 2) and they are not significantly different $\left(\mathrm{t}_{53}=0.65, \mathrm{p}=0.25 ; \mathrm{t}_{53}=0.26, \mathrm{p}=0.39\right.$, respectively). However, our power analysis shows that this lack of finding may be due to power issues because given our sample size, minimum detectable effect size is 0.7 which is fairly large. Thus, our sample size does not allow us to surely rule out the possibility that there is an effect of sorting in average information case.

\begin{tabular}{|c|c|c|c|c|}
\hline & SortAve & Ave & Pearson's chi-squared \\
\hline \multirow{2}{*}{ 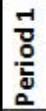 } & Said 20 & 3 & 8 & \multirow{2}{*}{$p=0.405$} \\
\hline & Said $<20$ & 18 & 26 & \\
\hline \multirow{2}{*}{ 弪 } & Said 20 & 5 & 9 & \multirow{2}{*}{$p=0.826$} \\
\hline & Said $<20$ & 16 & 25 & \\
\hline
\end{tabular}

\begin{tabular}{|c|c|c|c|c|}
\hline & SortAve & Ave & Pearson's chi-squared \\
\hline \multirow{2}{*}{ 굼 } & $>10$ & 7 & 14 & \multirow{2}{*}{$p=0.561$} \\
\hline & $<=10$ & 14 & 20 & \\
\hline \multirow{2}{*}{ 믈 } & $>10$ & 7 & 15 & \multirow{2}{*}{$p=0.428$} \\
\hline & $<=10$ & 14 & 19 & \\
\hline
\end{tabular}

Table 3: Comparison of extreme and sure cheater percentages for average and sorting average treatments.

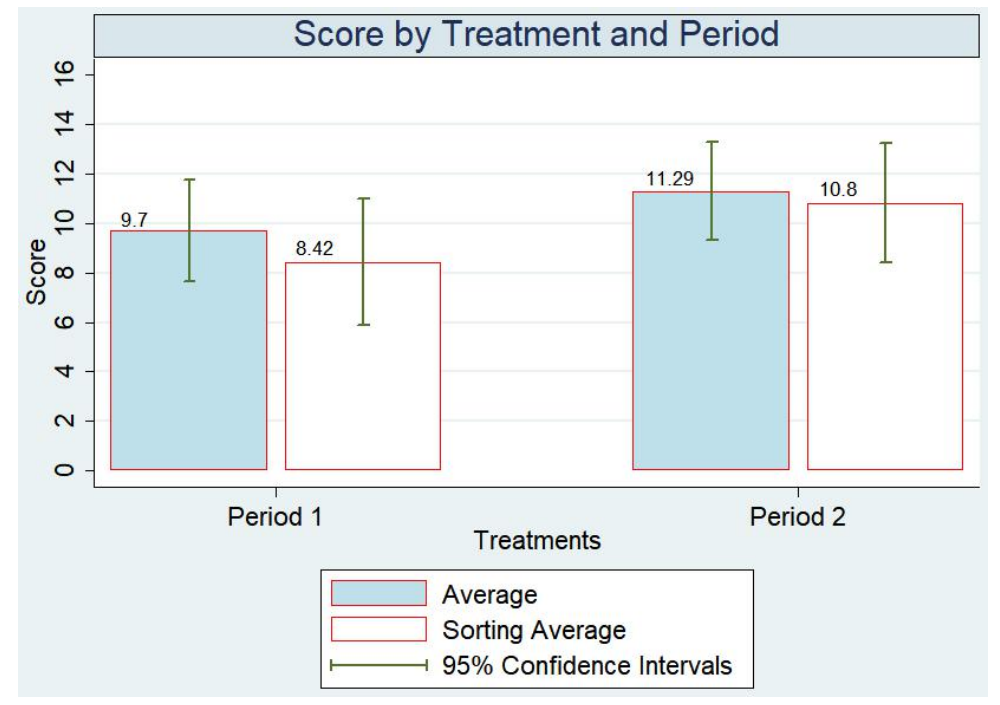

Figure 2: Reported period-wise scores for average and sorting average treatments.

Regarding the effect of maximum information, mean of the sorting maximum is expected to be higher in both periods than the mean of the maximum treatment. The reason is the difference of types existing in the groups. The ratios of extreme and sure-cheaters are significantly higher in the sorting maximum for both period 1 and $2\left(\chi^{2}(1,66)>6.49, \mathrm{p}<0.011\right.$ for all the comparisons, see Table 4). As Figure 3 shows, mean reports in the sorting maximum treatment in both periods are significantly higher than the means in the maximum treatment $\left(11.45\right.$ vs. $7.22 ; \mathrm{t}_{64}=2.58, \mathrm{p}=0.006$ for period $1 ; 15.21$ vs. 9.05 ; $\mathrm{t}_{64}=4.037, \mathrm{p}=0.001$ for period 2 ). 


\begin{tabular}{|c|c|c|c|c|}
\hline & & Sortmax & Max & Pearson's chi-squared \\
\hline \multirow{2}{*}{ 밈 } & Said 20 & 11 & 4 & \multirow{2}{*}{$p=0.009$} \\
\hline & Said $<20$ & 18 & 33 & \\
\hline \multirow{2}{*}{ N } & Said 20 & 16 & 6 & \multirow{2}{*}{$p=0.001$} \\
\hline & Said $<20$ & 13 & 31 & \\
\hline
\end{tabular}

\begin{tabular}{|c|c|c|c|c|}
\hline \multirow{3}{*}{ 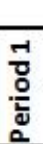 } & & Sortmax & Max & Pearson's chi-squared \\
\hline & $>10$ & 13 & 6 & \multirow{2}{*}{$p=0.011$} \\
\hline & $<=10$ & 16 & 31 & \\
\hline \multirow{2}{*}{ 금 } & $>10$ & 19 & 11 & \multirow{2}{*}{$p=0.004$} \\
\hline & $<=10$ & 10 & 26 & \\
\hline
\end{tabular}

Table 4: Comparison of extreme and sure cheater percentages for maximum and sorting maximum treatments.

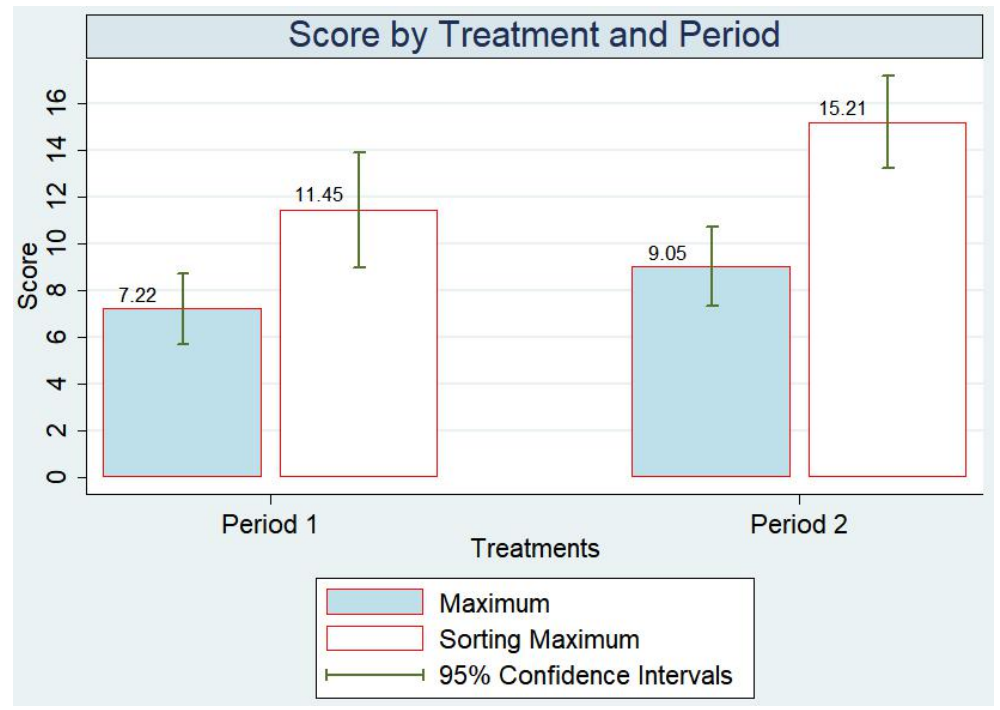

Figure 3: Reported period-wise scores for maximum and sorting maximum treatments.

In order to test whether sorting makes dishonesty more prevalent, we compare base treatment with the pooled sorting treatment. We first check whether scores of sorting treatment are drawn from the same population with other treatments. The null hypothesis cannot be rejected for base, average, maximum and sorting treatments for period 1 ( $\mathrm{KW}$ test $\chi^{2}=2.307, \mathrm{p}=0.51$; one-way $\operatorname{ANOVA~} \mathrm{F}(3,149)=1.53, \mathrm{p}=0.2$ ), while it is rejected for period $2\left(\mathrm{KW}\right.$ test $\chi^{2}=10.065, \mathrm{p}=0.018$; one-way $\operatorname{ANOVA~} \mathrm{F}(3,149)=3.39, \mathrm{p}=$ 0.019). This implies that sorting treatment in which more cheating is observed is significantly differentiated from the others.

Data shows that ratio of extreme cheaters is significantly more in the sorting treatment relative to the base treatment, while ratio of sure cheaters is not (Table 5). Moreover, as Figure 4 shows, period 1 scores are not significantly different across base and sorting treatments $(8.93$ vs. $10.18 ;$ t $80=0.794, p=$ 0.21), while period 2 scores in sorting treatment is significantly higher than scores in base treatment (10.78 vs. $\left.13.36 ; \mathrm{t}_{80}=1.82, \mathrm{p}=0.035\right)$. Based on our analyses, we find that allowing participants to sort into different informational environments exacerbates the level of dishonesty relative to no-information case. 


\begin{tabular}{|c|c|c|c|c|}
\hline & Base & Sorting & Pearson's chi-squared \\
\hline \multirow{2}{*}{ 믐 } & Said 20 & 3 & 14 & \multirow{2}{*}{$p=0.042$} \\
\hline & Said $<20$ & 29 & 36 & \\
\hline \multirow{2}{*}{$\frac{N}{\mathrm{D}}$} & Said 20 & 5 & 18 & \multirow{2}{*}{$p=0.045$} \\
\hline & Said $<20$ & 27 & 32 & \\
\hline
\end{tabular}

\begin{tabular}{|c|c|c|c|c|}
\hline \multirow{3}{*}{ 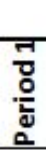 } & & Base & Sorting & Pearson's chi-squared \\
\hline & $>10$ & 9 & 20 & \multirow{2}{*}{ 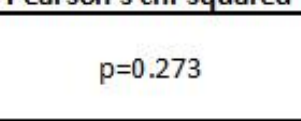 } \\
\hline & $<=10$ & 23 & 30 & \\
\hline \multirow{2}{*}{ № } & $>10$ & 11 & 26 & \multirow{2}{*}{$p=0.118$} \\
\hline & $<=10$ & 21 & 24 & \\
\hline
\end{tabular}

Table 5: Comparison of extreme and sure cheater percentages for base and sorting treatments.

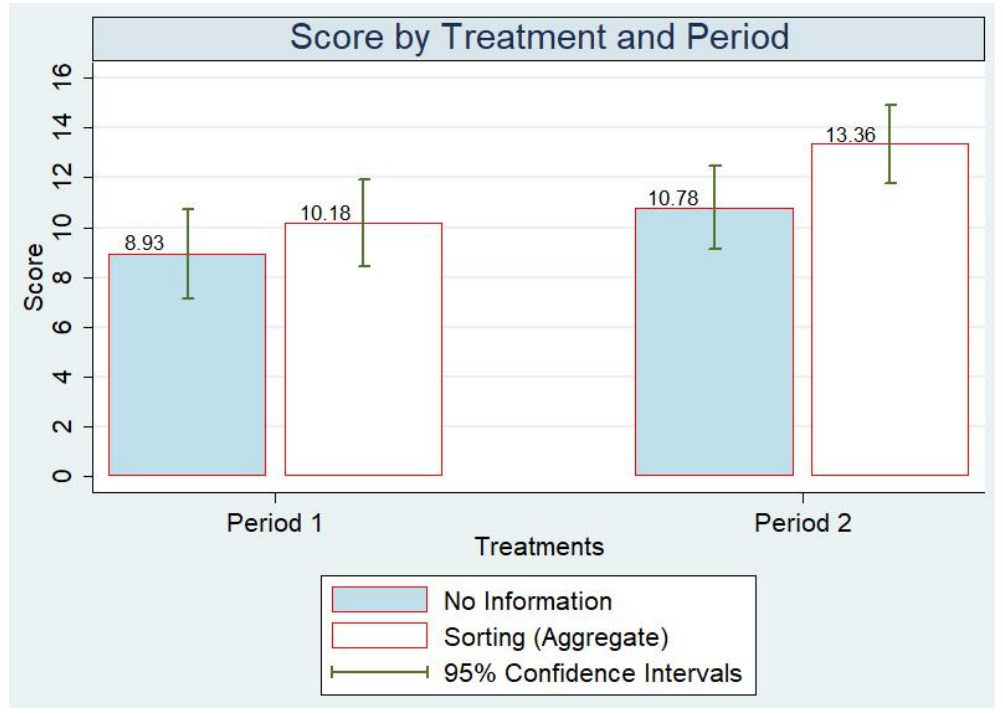

Figure 4: Reported period-wise scores for no information/base and aggregate sorting treatments.

\subsection{Why Is There More Dishonesty Under Sorting?}

The preceding results imply that sorting makes a difference in the level of dishonesty. Since participants sort into environments with different informational contents in the sorting treatment, we can firstly analyze their choices and see whether and how choices of these groups differ and secondly, examine who chooses which information.

We previously showed that the null hypothesis that scores of sorting treatment are drawn from the same population with other treatments is rejected for period 2. To further understand this differentiation, we separated sorting treatment into its subgroups and showed that the reason of negative differentiation of sorting treatment from other treatments is the choosers of maximum information. The KW and ANOVA tests with subgroups of sorting treatment reveal that, although no difference result still holds for period 1 $(\chi 2=4.311, \mathrm{p}=0.36 ; \mathrm{F}(4,148)=1.80, \mathrm{p}=0.13)$, for period 2 , the null hypothesis is rejected $(\chi 2=14.453$, $\mathrm{p}=0.006 ; \mathrm{F}(4,148)=4.15, \mathrm{p}=0.0033)$. Moreover, ANOVA results also show that only sorting maximum treatment leads to significantly higher dishonesty relative to the base treatment. 
Relative to the information about average, information regarding the maximum score can be considered somewhat redundant. The reason is that when a subject realizes in the first period that any number between 0 and 20 can be reported, it can be easily predicted that maximum would trivially be 20 . Thus, it can be argued that the average information is relatively more valuable than maximum information. However, \% 58 of the subjects (29 out of 50 subjects) chose maximum option. Moreover, the answers from surveys verify this argument because more than one third of the subjects who chose the average option emphasized that they chose average information because maximum information is obvious, not necessary, easily predictable etc. This implies that many of the maximum information choosers, if not most, chose what they chose most probably not because of its informational value but because of its psychic relief they expect to get by learning it although they more or less predicted it ex-ante. This is similar to the "license to cheat" effect found in Gino et al. (2013b). Thus, these observations also support the argument that sorting provides the opportunity to fulfill people's desire to seek justification for their dishonesty.

\subsubsection{Do Ones Who Select Different Information Behave Differently?}

When we compare the average reports of the subgroups in the sorting treatment across periods, our data revealed that in the sorting treatment, ex-post cheating behavior of the subgroups differ significantly (See Figure 5). First period average report of maximum information choosers is not significantly higher than the average report of average information choosers (8.42 vs. 11.44; t-test, $\left.\mathrm{t}_{48}=1.43, \mathrm{p}=0.079\right)$. This may be due to some maximum information choosers being reluctant to cheat without learning this information (or due to power issues since our analysis show that to be able to detect a medium effect size with sufficient power, we need $\mathrm{N}=104$ ). However, there is a significant difference in the second period ( 10.80 vs. 15.20 ; $\mathrm{t}$-test, $\mathrm{t}_{48}=2.43, \mathrm{p}=0.009$ ). These imply that ex-post behavior of these subgroups significantly differs from each other.

Our analyses also show that average information choosers do not change their behavior across periods while maximum information choosers inflate their scores in the second period which explains the overall increase in cheating level in the aggregate sorting treatment.

We first compared the percentages of the extreme cheaters across subgroups. In the first period, the percentage of extreme cheaters is higher among ex-post maximum information choosers than ex-post average information choosers but this difference is not statistically significant (Table $6 ; \chi^{2}(1,50)=3.377$, $\mathrm{p}=0.066$ ). However, this percentage is significantly higher among the ones who actually choose maximum information than the ones who actually choose average information (Table $\left.6 ; \chi^{2}(1,50)=4.51, p=0.034\right)$. In addition, we checked whether sure-cheaters chose the maximum information more than the rest. We found 
that the ratios of these choices do not differ significantly (Table $6 ; \chi^{2}(1,50)=0.67, p=0.413$ ) in the first period but in the second period, the percentage of sure-cheaters is significantly higher among the choosers of maximum information than the choosers of average information (Table $6 ; \chi^{2}(1,50)=5.05, \mathrm{p}=0.025$ ).

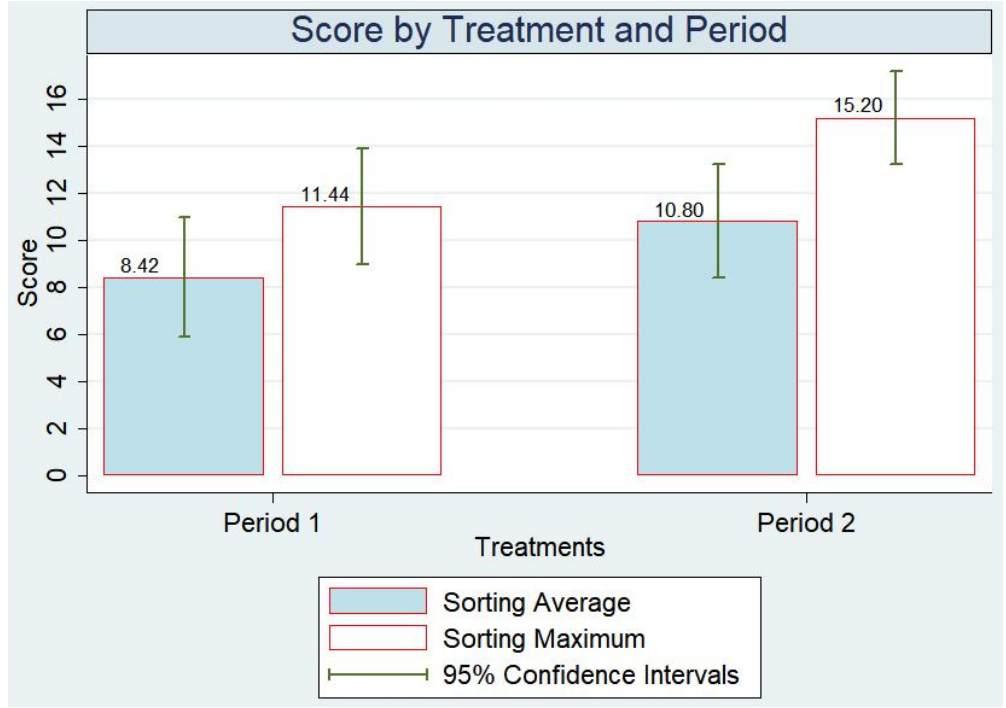

Figure 5: Reported period-wise scores for sorting average and sorting maximum treatments.

\begin{tabular}{|c|c|c|c|c|}
\hline & & SortAve & SortMax & Pearson's chi-squared \\
\hline \multirow{2}{*}{ 年 } & Said 20 & 3 & 11 & \multirow{2}{*}{$p=0.066$} \\
\hline & Said $<20$ & 18 & 18 & \\
\hline \multirow{2}{*}{$\begin{array}{l}\text { No } \\
\text { Dू } \\
\frac{2}{2}\end{array}$} & Said 20 & 4 & 14 & \multirow{2}{*}{$p=0.034$} \\
\hline & Said $<20$ & 17 & 15 & \\
\hline
\end{tabular}

\begin{tabular}{|c|c|c|c|c|}
\hline & & SortAve & SortMax & Pearson's chi-squared \\
\hline \multirow{2}{*}{ 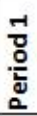 } & $>10$ & 7 & 13 & \multirow{2}{*}{$p=0.413$} \\
\hline & $<=10$ & 14 & 16 & \\
\hline \multirow{2}{*}{ 施 } & $>10$ & 7 & 19 & \multirow{2}{*}{$p=0.025$} \\
\hline & $<=10$ & 14 & 10 & \\
\hline
\end{tabular}

Table 6: Comparison of extreme and sure cheater percentages for sorting average and sorting maximum treatments.

To sum up, ex-post cheating level of maximum information choosers is significantly higher relative to average information choosers. The ratio of extreme cheaters and sure-cheaters are higher among maximum information choosers for the second period. These clearly show that the ones who drive the increase in cheating level in the sorting treatment are maximum information choosers.

\subsubsection{Who Chooses Which Information?}

We argued that the ones who tend to cheat more or would like to cheat more comfortably or both are more likely to choose maximum information. The results support this argument. First, the ones who cheat to the maximum possible extent in the first period chose to see the maximum information more. One possible reason for this is to legitimize their extreme dishonesty by observing someone who took the same action. Second, the ones who chose to see the maximum information reported significantly higher than the 
average information choosers in period 2. There are at least two observations driving this result: 1 . There are more extreme cheaters in this group and they keep reporting the extreme score in the second period. 2. Increase in across-period scores for not-sure-cheaters (reporting 10 or less) is significantly higher among the maximum information choosers than the average information choosers ( 2.78 vs. 6.75 on average from period 1 to period 2 , respectively; $\mathrm{t}_{28}=2.058, \mathrm{p}=0.0245$ ). Third, we can make another definition of being a cheater by looking at the aggregate scores/earnings. Since there is no one who reported scoring totally more than 15 in the control, we can say that anyone who totally reports more than 15 in the treatments can be categorized as a cheater. Based on this definition, in the sorting treatment, the percentage of maximum information choosers among cheaters $(71 \%, 20$ out of 28$)$ is significantly higher than the percentage of maximum information choosers among non-cheaters $(41 \%, 9$ out of 22$), \chi^{2}(1,50)=4.71, p=0.03$. Last but not least, we also compared ratios of extreme cheaters in at least one period across treatments. There are 5, $10,6,5$ and $17(5+17=22)$ people of this type in the base, average, maximum, sorting average and sorting maximum (aggregate sorting) treatments, respectively. Notably, the following pairwise comparisons of treatments revealed that these ratios are significantly higher in the latter $(\mathrm{p}<0.015$ for all): Base and sorting; maximum and sorting maximum; sorting average and sorting maximum.

One can argue that it is not that subjects choose maximum information to cheat more comfortably, instead they cheat more because they observe an extreme cheater. First, it is likely that both factors played a role. Second, subjects had to choose one of the alternatives which implies a conscious determination of what they would like to observe. Thus, we argue that choosing was intentional and this intention effect was stronger than observation effect. Third, we compared the incremental increases in scores across periods in the maximum and sorting maximum treatments. If subjects increase their reports only due to their observations of maximum information, then these two increments should not differ across these treatments. However, if they increase their scores by intentionally choosing maximum information, we should see a higher increment in the sorting maximum treatment. When we filter the data and we are only left with not-sure-cheaters who have non-negative increase in their scores, we confirmed that increment in sorting maximum treatment is significantly higher than the increment in maximum treatment (8.14 vs. 3.6; $\left.\mathrm{t}_{37}=-2.89, \mathrm{p}=0.003\right)$.

\section{Discussion and Conclusion}

People regularly sort into and out of different environments and they frequently choose to be in environments that are aligned with their preferences. This implies that people who show up in an environment are not likely to be a random sample of population. Rather, they are most likely the ones whose preferences are aligned with the information this environment delivers to its members. This 
argument is also valid for the formation of people's moral codes and preferences for honesty. ${ }^{10}$ Motivated by this observation of endogenous selection, we argue that real-world outcomes in terms of unethical behavior may turn out to be substantially different from the patterns of dishonest behavior of the typical individual in the subject pool. However, much of the existing literature focuses on how randomly selected subjects behave under different informational situations and in almost none of these studies, subjects are allowed to choose which information they want to be exposed to. Subjects find themselves in one particular informational situation and have to make choices given this imposed information that they may prefer to disregard outside the laboratory. Thus, incorporating sorting into dishonesty research better captures what actually happens in real-life situations.

In this study, we experimentally studied whether and how prevalence of unethical behavior is affected if people are allowed to sort into environments having different social information, namely average and extreme behavior. Consistent with our expectations, cheating behavior of people who are imposed average information do not differ from the behavior of the ones who sort into the average information environment, while the ones who chose to see the maximum information engage in unethical behavior significantly more than people who are imposed maximum information. We further find that sorting increases the overall level of cheating relative to the no information case and this more prevalent dishonesty is mainly driven by the ones who chose to see maximum information.

Our main findings seem relevant in several ways. First, randomization paradigm in experimental studies may not capture what actually happens in real-life situations due to people's ability to sort into and out of environments. This frequently disregarded aspect may play an important role in ethical decision making context. Our findings potentially imply that the extent of dishonesty found in the literature investigating the effect of providing social information may be an underestimate of actual level of dishonest behavior in real-world situations. Second, the fact that maximum information choosers are the main driving force behind more prevalent dishonesty under sorting implies that if there is unethical conduct and its information is somewhat accessible, especially prospective cheaters may utilize this information to rationalize their subsequent dishonest behavior. From the organizational perspective, this strong tendency of selective perception reemphasizes a well-known phenomenon: Putting most of the efforts into preventing unethical acts, having deterrent policies, and informing everyone about these in advance are the first priorities but when there is inevitably any unethical act, these policies should be consistently enforced and their consequences should be clearly communicated. Moreover, if revealed

\footnotetext{
${ }^{10}$ One can argue that the reverse causation is also true such that the environments in which people happen to be shape their behavior. As mentioned, emergence of one's choices is most probably driven by mutual interaction of these two components but this does not invalidate selection phenomenon that dominantly occurs initially.
} 
information, especially information about top performers, can be perceived as an undeserved outcome by some people, it can get them off course. Thus, policy implication of this observation is that revealing extreme performances in organizations should be considered carefully since for some people, it may serve as a justification for dishonest behavior.

Although our findings that show the potential critical role of sorting in the context of dishonesty are promising, further research is needed especially with greater sample sizes. This is important to have sufficiently powered design to rule out false negatives and to be able to interpret our positive results more confidently.

There are some novel and promising technical extensions that can be done for future research. For instance, it would be worthwhile to analyze which information people pay more attention to by using either a kind of costly information acquisition mechanism or eye tracking method. Moreover, in order to understand individuals' behavior in time, repeated tasks can be employed which will shed light on the dynamics of prevalence of dishonesty. Last but not least, our design did not allow subjects to select no information. Since people might prefer not to see any information in real world, it would be interesting to see the extent of dishonesty in this case.

Although it is difficult to cover real world's much more complex decision situations, we consider our analysis as a first step in illustrating how introducing a simple sorting opportunity can substantially change results and conclusions they imply. In this paper, we focused on sorting based on available information and its possible effects, but our argument may apply to a variety of settings in which different factors that potentially affect dishonest behavior are provided exogenously. For example: Groups are formed by the experimenter; people make decisions in the existence of beneficiaries; and people are given the option of doing good ex-post. All these factors can be endogenized by providing each of these variables as options and subjects can be allowed to choose the environments in which they would like to make decisions. Since examining behavior across environments with and without sorting helps to discriminate different motives regarding dishonest behavior, we believe that pursuing further studies in this line of research is worthwhile. 


\section{REFERENCES}

Abeler, J., Nosenzo D. \& Raymond C. (2016). Preferences for truth-telling. Forthcoming, Econometrica.

Ahn, T. K., Isaac, R., \& Salmon, T. C. (2008). Endogenous group formation. Journal of Public Economic Theory, 10(2), 171-194.

Becker, G.S. (1968). Crime and punishment: An economic approach. Journal of Political Economy, 76, 169-217.

Blackburn, J., Kourtellis, N., Skvoretz, J., Ripeanu, M., \& Iamnitchi, A. (2014). Cheating in online games: a social network perspective. ACM Transactions on Internet Technology (TOIT), 13(3), 9.

Charness, G., Masclet, D., \& Villeval, M. C. (2013). The dark side of competition for status. Management Science, 60(1), 38-55.

Cialdini, R.B., Reno, R.R., \& Kallgren, C.A. (1990). A focus theory of normative conduct: Recycling the concept of norms to reduce littering in public places. Journal of Personality and Social Psychology, 58, 10151026.

Cojoc, D., \& Stoian, A. (2014). Dishonesty and charitable behavior. Experimental Economics, 17(4), 717-732.

Dana, Jason, Daylian M. Cain, and Robyn M. Dawes. 2006. "What You Don’t Know Won’t Hurt Me: Costly (but quiet) Exit in Dictator Games." Organizational Behavior and Human Decision Processes 100 (2): 193-201

Dana, Jason, Roberto A. Weber, and Jason Xi Kuang. 2007. "Exploiting Moral Wiggle Room: Experiments Demonstrating an Illusory Preference for Fairness." Economic Theory 33 (1): 67- 80.

Diekmann A., Przepiorka W., Rauhut H. (2015) Lifting the veil of ignorance: An experiment on the contagiousness of norm violations. Rationality and Society, 27(3):309-333.

Faul, F., Erdfelder, E., Lang, A. G., \& Buchner, A. (2007). G*Power 3: A flexible statistical power analysis program for the social, behavioral, and biomedical sciences. Behavior Research Methods, 39, 175-191.

Fischbacher, U., \& Föllmi-Heusi, F. (2013). Lies in disguise - an experimental study on cheating. Journal of the European Economic Association, 11(3), 525-547.

Fosgaard, T. R., Hansen, L. G., \& Piovesan, M. (2013). Separating Will from Grace: An experiment on conformity and awareness in cheating. Journal of Economic Behavior \& Organization, 93, 279-284.

Gino, F., Ayal, S., \& Ariely, D. (2009). Contagion and differentiation in unethical behavior. The effect of one bad apple on the barrel. Psychological Science, 20(3), 393-398.

Gino, F., Ariely, D., (2012). The dark side of creativity: Original thinkers can be more dishonest. Journal of Personality and Social Psychology, 102 (3), 445-459.

Gino, F., Ayal, S., \& Ariely, D. (2013a). Self-serving altruism? The lure of unethical actions that benefit others. Journal of Economic Behavior \& Organization, 93, 285-292.

Gino F., Krupka E. L., Weber R. A. (2013b) License to Cheat: Voluntary Regulation and Ethical Behavior. Management Science, 59(10):2187-2203

Gino, F., Norton, M. I., \& Weber, R. A. (2016). Motivated Bayesians: Feeling moral while acting egoistically. The Journal of Economic Perspectives, 30(3), 189-212.

Gneezy, U. (2005). Deception: The Role of Consequences. American Economic Review 95: 384-94.

Gneezy, U., Kajackaite, A., \& Sobel, J. (2018). Lying Aversion and the Size of the Lie. American Economic Review, 108(2), 419-53.

Grolleau G., Kocher M. G., Sutan A. (2016) Cheating and Loss Aversion: Do People Cheat More to Avoid a Loss?. Management Science, 62(12), pp. 3428-3438 
Grossman, Zachary. 2014. "Strategic Ignorance and the Robustness of Social Preferences." Management Science 60 (11): 2659-2665.

Gürerk, Ö., Irlenbusch, B., \& Rockenbach, B. (2006). The competitive advantage of sanctioning institutions. Science, 312(5770), 108-111.

Haigner, S., Kocher, M. G., \& Sutter, M. (2006). Choosing the stick or the carrot? Endogenous institutional choice in social dilemma situations. Centre for Economic Policy Research.

Houser, D., Vetter, S., \& Winter, J. (2012). Fairness and cheating. European Economic Review, 56(8), 16451655.

Innes, R., \& Mitra, A. (2013). Is dishonesty contagious? Economic Inquiry, 51(1), $722-734$.

Irlenbusch, B., \& Villeval, M. C. (2015). Behavioral ethics: how psychology influenced economics and how economics might inform psychology?. Current Opinion in Psychology, 6, 87-92.

Khalmetski, K., \& Sliwka, D. (2017). Disguising Lies-Image Concerns and Partial Lying in Cheating Games (No. 6347). CESifo Group Munich.

Kroher, M., \& Wolbring, T. (2015). Social control, social learning, and cheating: Evidence from lab and online experiments on dishonesty. Social Science Research, 53, 311-324.

Lazear, E. P., Malmendier, U., \& Weber, R. A. (2012). Sorting in experiments with application to social preferences. American Economic Journal: Applied Economics, 4(1), 136-163.

Lefebvre, M., Pestieau, P., Riedl, A., \& Villeval, M. C. (2015). Tax evasion and social information: an experiment in Belgium, France, and the Netherlands. International Tax and Public Finance, 22(3), 401-425.

Mazar, N., Amir, O., \& Ariely, D. (2008). The dishonesty of honest people: A theory of self-concept maintenance. Journal of Marketing Research, 45(6), 633-644.

Niederle, M., \& Vesterlund, L. (2007). Do women shy away from competition? Do men compete too much? The Quarterly Journal of Economics, 122(3), 1067-1101.

Rauhut, H. (2013). Beliefs about Lying and Spreading of Dishonesty: Undetected Lies and Their Constructive and Destructive Social Dynamics in Dice Experiments. PLoS ONE, 8(11): e77878. doi:10.1371/journal.pone. 0077878

Shalvi, S., Dana, J., Handgraaf, M.J.J., De Dreu, C.K.W. (2011). Justified ethicality: observing desired counterfactuals modifies ethical perceptions and behavior. Organizational Behavior and Human Decision Processes, 115, 181-190.

Shalvi S., Gino F., Barkan R., Ayal S. (2015). Self-Serving Justifications: Doing Wrong and Feeling Moral. Current Directions in Psychological Science, Vol. 24(2) 125- 130.

Slonim, R., \& Garbarino, E. (2008). Increases in trust and altruism from partner selection: Experimental evidence. Experimental Economics, 11(2), 134-153.

Villeval, M. C., \& Eriksson, T. (2004). Other-Regarding Preferences and Performance Pay: An Experiment on Incentives and Sorting (No. 1191). IZA Discussion paper series.

Wason, P. C. (1960). On the failure to eliminate hypotheses in a conceptual task. Quarterly Journal of Experimental Psychology, 12(3), 129-140. 
APPENDIX - 1A: How the Experiment Proceeds

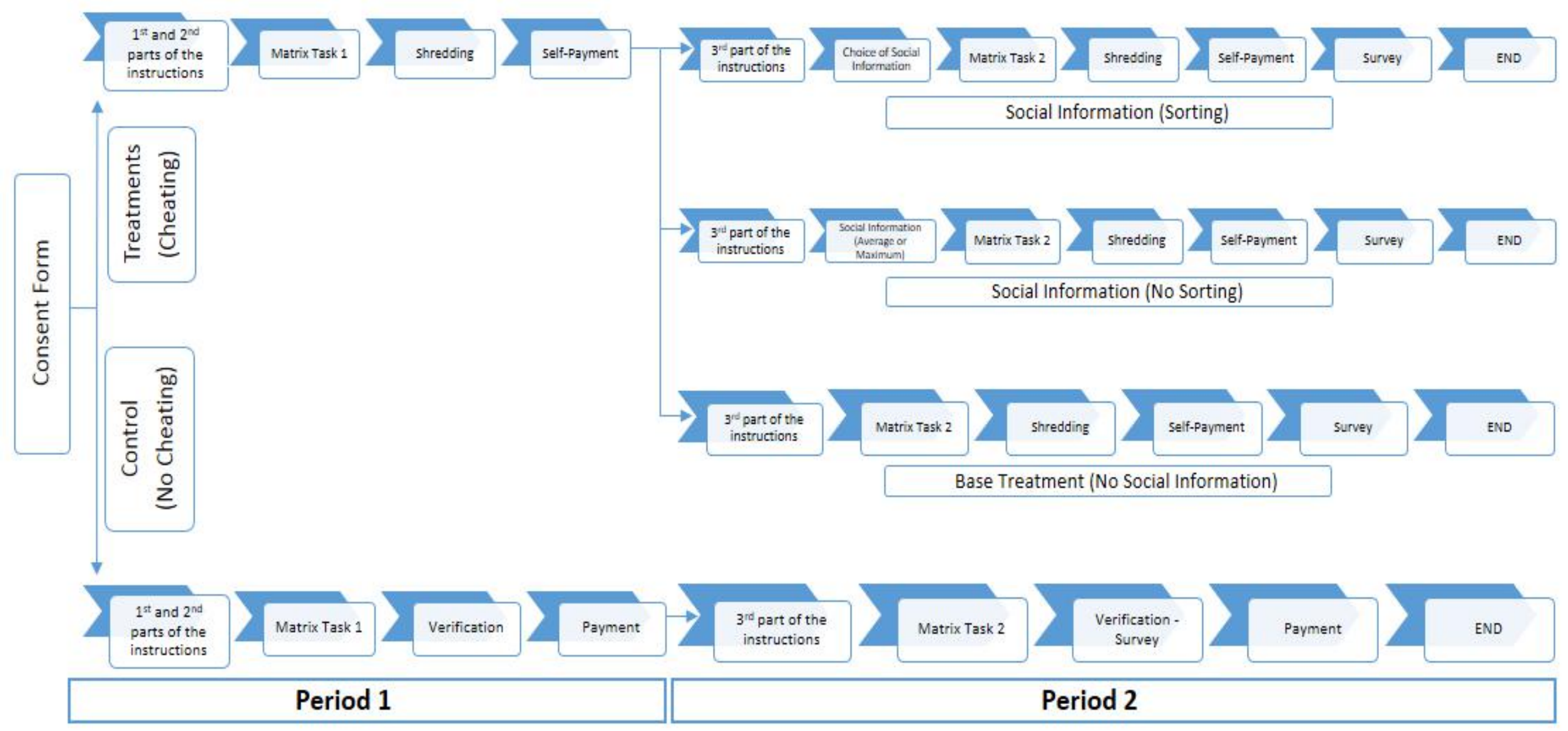




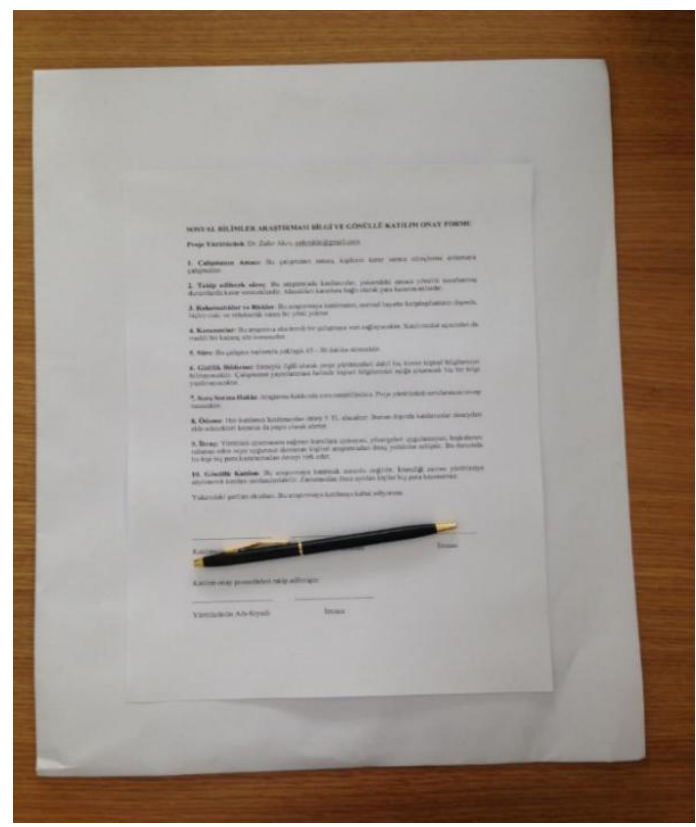

This is what participants saw on the table when they arrived at the lab.

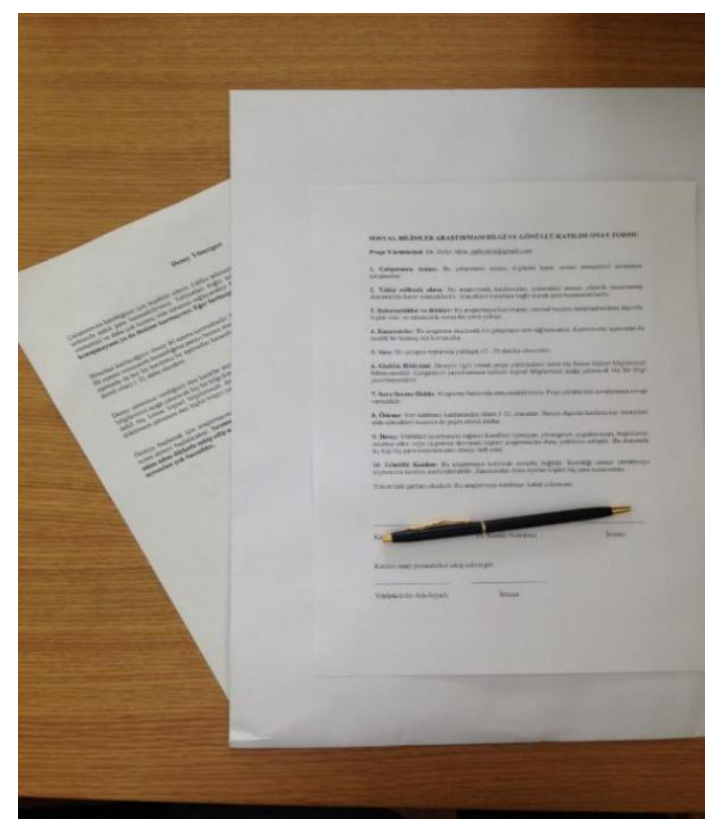

One page instructions sheet (including $1^{\text {st }}$ and $2^{\text {nd }}$ parts of the instructions back to back on this page) was located under the big white envelope. After filling out consent form at the top, instructions were read aloud and subjects followed.

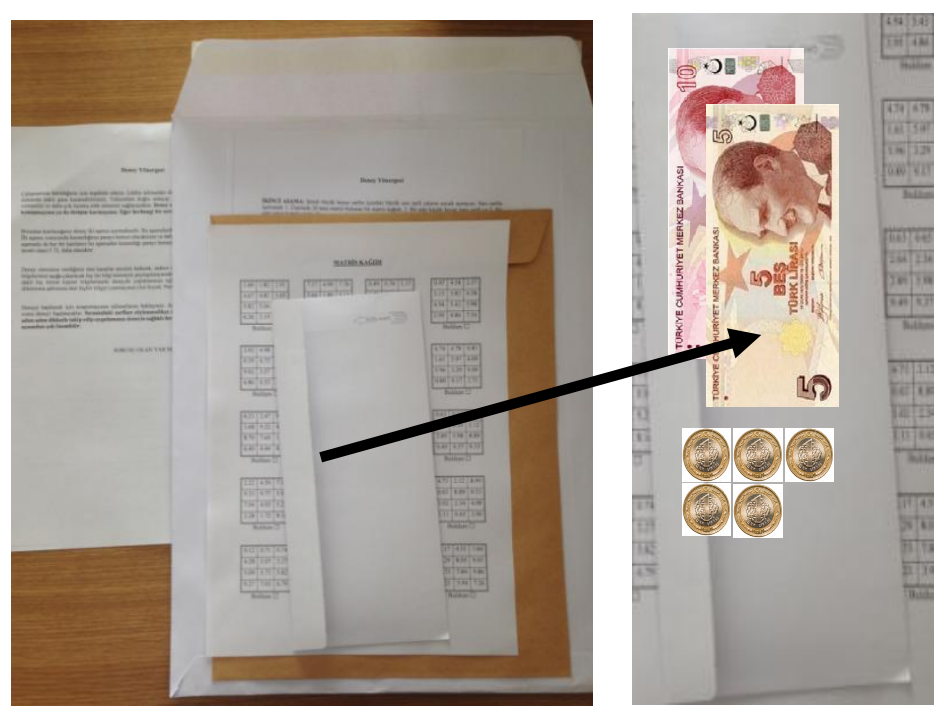

Inside the big white envelope, a yellow envelope, $1^{\text {st }}$ matrix sheet, $1^{\text {st }}$ money envelope and $3^{\text {rd }}$ part of the instructions were placed. Inside the money envelope, there were one 10TL bill, one 5TL bill and five 1TL coins. 


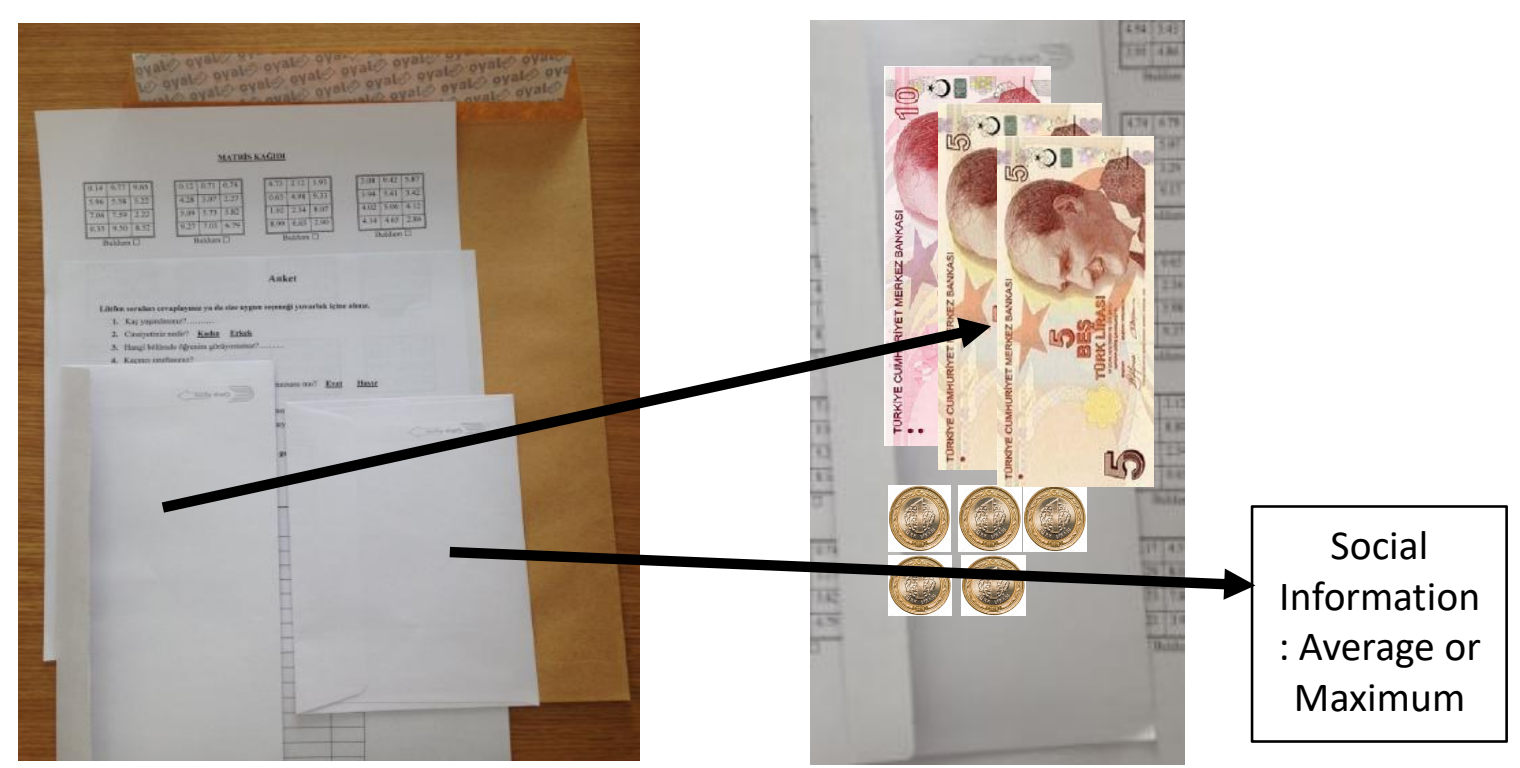

In no sorting treatments, inside the yellow envelope, $2^{\text {nd }}$ matrix sheet, survey sheet, $2^{\text {nd }}$ money envelope and information envelope (in the base treatment, there was no information envelope) were placed. Inside the money envelope, there were one 10TL bill, two 5TL bills and five 1TL coins.

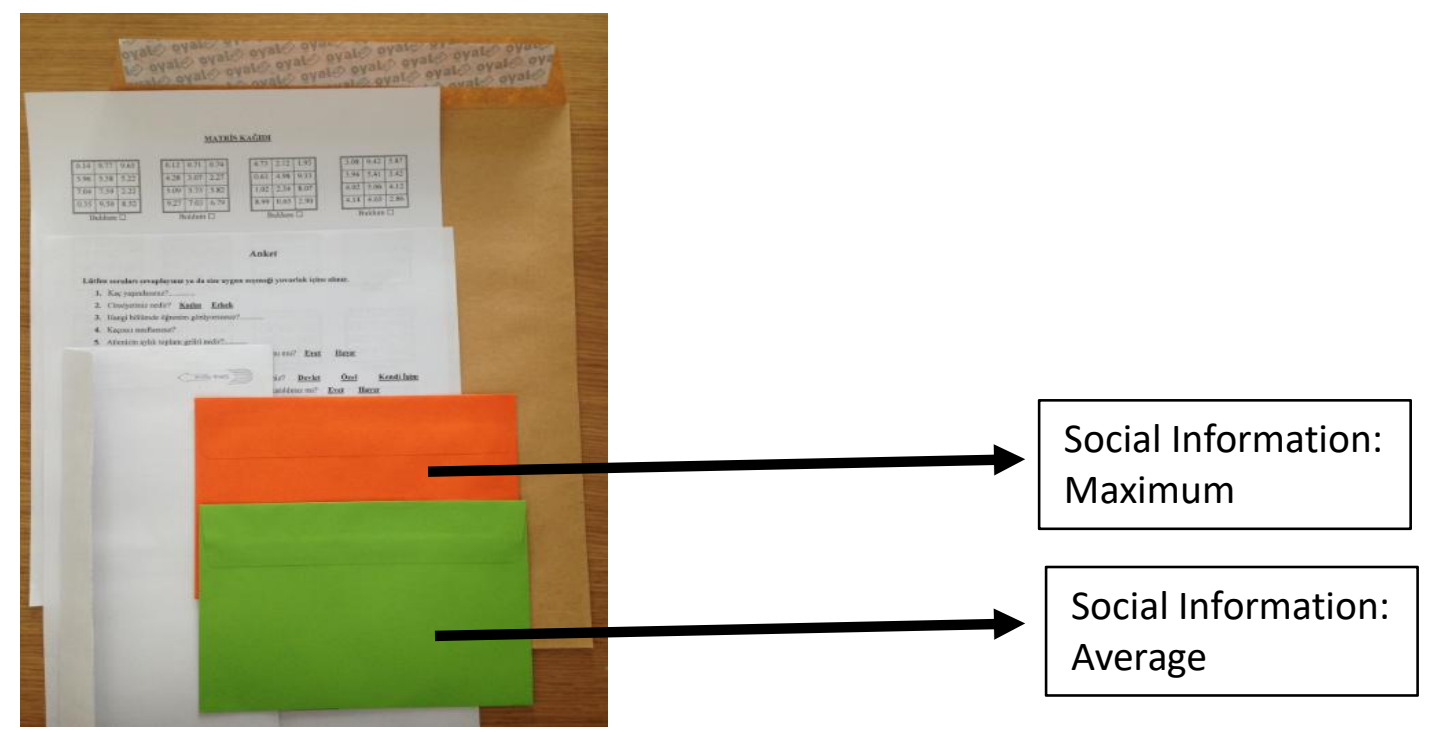

In sorting treatment, instead of one white information envelope, there were one green and one orange envelope -both sealed- that contain average information and maximum information slip, respectively. Subjects were instructed to open only one of them just before they start the $2^{\text {nd }}$ matrix task. 


\section{APPENDIX - 2: Instructions \\ (Translated from Turkish)}

\section{FIRST PART:}

Thank you for your participation. Please follow the instructions carefully. You can earn substantial amount of money in this experiment. Understanding the instructions correctly will enable you to make better decisions to increase your earnings. Do not communicate with other participants during the experiment. If you have any questions, raise your hand and wait for the experimenter.

The experiment you are about to participate includes two phases. You will be informed about each of them. At the end of the first phase, you will be paid what you earn and then second phase will start. You will be paid what you earn and additional 5 Turkish Lira (TL) show up fee at the end of the second phase.

All the decisions you make during the experiment will be kept anonymous, they will be used for research purposes only and will not be shared with anyone. No one including the researchers will be able to match what you did in the experiment with your identity. Do not write any of your information to any of the documents during the experiment (name, surname, ID number, e-mail, etc.).

Please wait for the experimenter to start. After going over the instructions, the experiment will start. Please do not open the envelopes on your table unless told. Listening and reading instructions and following them carefully as the experimenter explains are very important for the experiment to proceed in a timely manner.

\section{Do you have any questions?}

SECOND PART: You will find the followings in the envelope on your table: 1. One-page matrix sheet, 2. One small white money envelope and 3. One big yellow envelope. Do not open any of the envelopes unless told. First of all, you will be requested to work on the matrix task in the big white envelope. Please see an example of the matrix below.

\begin{tabular}{|c|c|c|}
\hline \multicolumn{3}{|c|}{ Example } \\
\hline 3.91 & 0.82 & 3.75 \\
\hline 1.11 & 1.69 & 7.94 \\
\hline 3.28 & 2.52 & 6.25 \\
\hline 9.81 & 6.19 & 2.46 \\
\hline
\end{tabular}

What you will do in this task is to find two numbers that add up to 10. When you are instructed, you find these numbers, circle them and then mark the "I found" box. 


\begin{tabular}{||l|l|l|}
\hline \multicolumn{3}{|c|}{ Example } \\
\hline \hline \hline 3.91 & 0.82 & 3.75 \\
\hline 1.11 & 1.69 & 7.94 \\
\hline 3.28 & 2.52 & 6.25 \\
\hline 9.81 & 6.19 & 2.46 \\
\hline \hline \multicolumn{3}{|c|}{ I found } \\
\hline
\end{tabular}

You will earn $1 \mathrm{TL}$ for each of the correctly matrix. You will have 5 minutes to work on the matrices. After 5 minutes, you will have 1 minute to evaluate your own performance and you will earn money based on it. Please do not start the experiment unless told. Do not write any of your information to any of the documents (matrix sheet, envelope, etc.) during the experiment (name, surname, ID number, e-mail, etc.).

After 5 minutes you work on the matrix sheet, the experiment will proceed as follows:

1. You will count how many matrices you solved correctly in 1 minute by yourself;

2. At the end of 1 minute, you will stand up, go to the shredder at the back of the room, shred your matrix sheet, and then go back to your seat;

3. You take and open the small money envelope from the big white envelope (There are one $10 \mathrm{TL}$, one 5 TL bill and 5 one TL coins in the money envelope, totally $20 \mathrm{TL}$ ). You take $1 \mathrm{TL}$ from the money envelope for each matrix you solved correctly. Then, you seal the money envelope and you place it into the big white envelope;

4. You wait for the experimenter for further instructions.

You will be reminded each of these steps by the experimenter.

Do not talk to anybody during the experimenter. If you have any questions at any time, raise your hand and wait for the experimenter. Do not ask questions out loud.

\section{Do you have any questions?}

THIRD PART: Now take the yellow envelope out but do not open it. You will find the followings in the yellow envelope: 1. One-page matrix sheet, 2. One small white money envelope and 3. One page survey sheet and 4. One small square information envelope (ONLY IN SORTING TREATMENT: Two small square information envelopes, one orange and one green). In this phase, you will work on a different matrix task again. After 5 minutes, you will have 1 minute to evaluate your own performance and you will take $1 \mathrm{TL}$ for each of the correctly solved matrix from the money envelope. Please do not open the envelopes unless instructed. Do not write any of your information to any of the documents (matrix sheet, envelope, etc.) during the experiment (name, surname, ID number, e-mail, etc.). 
(ONLY IN AVERAGE TREATMENT: Now open the small square information envelope before starting the second matrix task. You will be given information about the average earnings of the participants in the second matrix task you are about to start who joined the exact same experiment before. After reading the information, place the information sheet back into the small envelope. Then, put the small envelope back into the yellow envelope.

(ONLY IN MAXIMUM TREATMENT: Now open the small square information envelope before starting the second matrix task. You will be given information about the earning of the person who earns the highest amount in the second matrix task you are about to start among the participants who joined the exact same experiment before. After reading the information, place the information sheet back into the small envelope. Then, put the small envelope back into the yellow envelope.

(ONLY IN SORTING TREATMENT: In a moment, you will choose only one of the two small colored information envelopes that are sealed, open it and you will read the information within it. The information sheet in the orange envelope includes the earning of the person who earns the highest amount in the second matrix task you are about to start among the participants who joined the exact same experiment before. The information sheet in the green envelope includes the average earnings of the participants in the second matrix task you are about to start who joined the exact same experiment before. After reading the information that you would like to learn, place the information sheet you read back into the small envelope. Then, put the small envelope back into the yellow envelope. Both orange and green envelopes are sealed. You should just open one of them. Do not open the other one.

After 5 minutes you work on the matrix sheet, the experiment will proceed as follows:

1. You will count how many matrices you solved correctly in one minute by yourself;

2. At the end of one minute, you will stand up, go to the shredder at the back of the room, shred your matrix sheet, and then go back to your seat;

3. You take and open the small money envelope from the yellow envelope (There are one $10 \mathrm{TL}$, two 5 TL bills and 5 one TL coins in the money envelope, totally 25 TL). You first take 5 TL show up fee from the money envelope. You then take $1 \mathrm{TL}$ from the money envelope for each matrix you solved correctly. Then, you seal the envelope and you place it into the yellow envelope;

4. Finally, take the survey page and fill it out. After you fill it out, place it into the yellow envelope. Without sealing the yellow envelope, place it into the big white envelope. Seal the big white envelope. Then you will leave the room after you place the big white envelope in the recycling box located next to the exit door.

You will be reminded each of these steps by the experimenter.

Do not talk to anybody during the experimenter. If you have any questions at any time, raise your hand and wait for the experimenter. Do not ask questions out loud.

\section{Do you have any questions?}

